\title{
PENGARUH INJEKSI AIR DAN PENGATURAN DERAJAT PENGAPIAN TERHADAP PENURUNAN KONSUMSI BAHAN BAKAR MESIN SEPEDA MOTOR
}

\author{
Myson
}

\begin{abstract}
Water injection is a hydraulic technique of injecting water into the combustion chamber with the purpose to decrease the amount of fuel sipped by pistons during the expansion, and replaced it with water directly injected to combustion chamber. This water injection process also reduce temperature in combustion chamber. Besides degree of ignition is having a significant effect on quality of combustion earning. Angle of earlier ignition will cause increase of combustion pressure speed, which in turn makes pressure result of combustion in excelsior cylinder. But if degree of ignition in backs into, hence time required by fuel for combustible become smaller and fuel can be combustible at outlet. Result from test conducted by moving forward degree of ignition and water injection done at honda mega-pro and honda supra fit showed that efficiency of engine can be improved. For motorbike Honda Mega-Pro result showed improved of specific fuel consumtion to torsion equal to 47,82\% with treatment of water injection mixed with alcohol with ratio 60:40 at degree of ignition moved forward by 3 degree of at burden $1 \mathrm{KW}$ (Kilo Watt). For Honda Supra Fit improved of specific fuel consumtion to torsion 25,14 \% at treatment of water injection mixed with by alcohol at ratio 80:20 with degree of ignition is moved forward 5 degree of at burden $1 \mathrm{KW}$.

Keyword: Water injection, degree of ignition, improved efficiency, motorcycle engine
\end{abstract}

\section{PENDAHULUAN}

Bahan bakar minyak yang mahal dan terbatas selayaknya dimanfaatkan se efisien mungkin dengan menerapkan prinsip konservasi energi. Teknologi pembakaran pada mesin sepeda motor banyak menggunakan premium 88 yang bersubsidi, khusus mesin 4 tak efisiensinya berkisar antara $60 \%$ hingga $70 \%$. Hal ini menyebabkan konsumsi bahan bakar menjadi lebih banyak dari yang seharusnya. Untuk itu perlu suatu inovasi agar mesin sepeda motor khususnya yang efisiensinya masih rendah $(60 \%$ - $70 \%)$ dapat dilakukan peningkatan efisiensi bahan bakarnya.

\section{Permasalahan}

Dari jumlah sepeda motor yang berlalu-lalang tersebut yang diproduksi diatas tahun 2006 hanya berkisar $\pm 10 \%$, artinya sepeda motor yang masih menggunakan mesin dengan tingkat efisiensi yang berkisar 60-70\% masih sangat banyak $( \pm 90 \%)$. Dengan efisiensi tersebut maka 30-40 \% bahan bakar yang masuk keruang bakar akan terbuang. Jika setiap sepeda motor mengkonsumsi 1 liter bahan bakar maka yang dapat diubah menjadi energi mekanis pada mesin sepeda motor tersebut hanya 0,6 sampai 0,7 liter saja.

Adapun tujuan dari penelitian ini adalah: 1) Mendapatkan efisiensi konsumsi bahan bakar. 2) Mendapatkan daya dan torsi yang maksimal.

Adapun manfaat dari penelitian ini adalah: 1) Agar masyarakat dapat berhemat biaya transport. 2) Pemerintah dapat mengurangi subsidi untuk bahan bakar kendaraan bermotor. 


\section{STUDI PUSTAKA}

\section{Siklus Otto}

Siklus mesin 4-tak dapat dijabarkan dalam termodinamika sebagai 6 fase siklus Otto standar-udara (air-standard Otto Cycle). 6 fase siklus Otto ini dapat digambarkan dalam diagram PVT (pressure, volume, temperature) sebagai berikut.

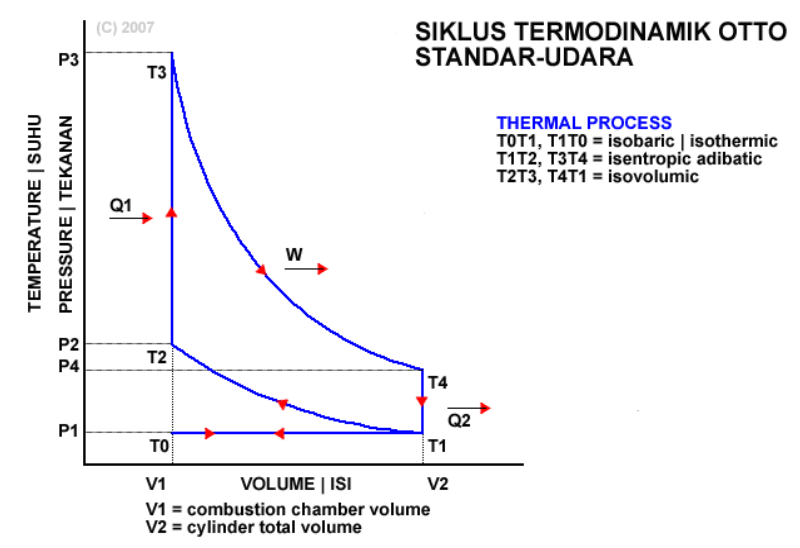

Gambar 1. Siklus Thermodinamik Otto Standar-Udara

$\mathrm{f}(\mathrm{P}, \mathrm{V}, \mathrm{T}, \mathrm{m})=0$

dengan formula dasar keseimbangan termodinamik (themodynamic equilibrium)

$\mathrm{P} . \mathrm{V}=\mathrm{m} \cdot \mathrm{R} \cdot \mathrm{T}$

dimana,

$\mathrm{p}=$ pressure.

$\mathrm{T}=$ temperature (suhu).

$\mathrm{V}=$ volume.

$\mathrm{m}=$ mass.

$\mathrm{R}=$ konstanta gas universal.

Jika kandungan panas jenis gas diperhitungkan, maka formula diatas menjadi:

$\mathrm{P} \cdot \mathrm{V}^{\mathrm{h}}=\mathrm{m} \cdot \mathrm{R} \cdot \mathrm{T}$

dimana,

$\mathrm{k}$ atau $\mathrm{h} \quad=\mathrm{cp} / \mathrm{cv}$

$\mathrm{R} \quad=\mathrm{cp}-\mathrm{cv}$, utk gas ideal

dimana,

$\mathrm{h} \quad=$ panas jenis (specific heat).

c = kapasitas panas jenis (specific heat capacity) gas, yaitu panas yang dibutuhkan

untuk menaikan 1 derajat suhu suatu gas.

$\mathrm{cp}=\mathrm{c}$ pada tekanan tetap; kapasitas panas jenis isobarik.

$\mathrm{cv}=\mathrm{c}$ pada volume tetap; kapasitas panas jenis isovolumik.

$\mathrm{k}=$ konstanta (constant).

$\mathrm{H}=\mathrm{U}+\mathrm{P} . \mathrm{V}$

dimana,

$\mathrm{H}=$ entalpi (enthalpy), kandungan panas (heat content).

$\mathrm{U}=$ internal energy. 


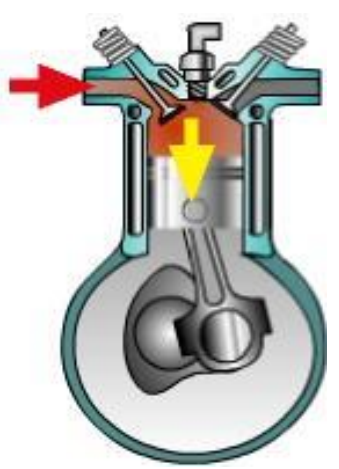

Gambar 2. Langkah Isap

Pada gambar 2 adalah langkah pemasukan udara dan bahan bakar pada tekanan dan suhu tetap dari karburator ke ruang bakar. Klep masuk terbuka dan piston turun 180 derajat. Pada proses ini tekanan gas dan suhu gas tetap dan sama dengan lingkungan. Volume silinder (V) membesar dari V1 ke V2, sehingga masa gas campuran bahan bakar dan udara dalam silinder bertambah dari $\mathrm{m} 1 \mathrm{ke} \mathrm{m} 2$.

$\mathrm{P} 1 .(\mathrm{V} 2-\mathrm{V} 1)=(\mathrm{m} 2-\mathrm{m} 1) \cdot \mathrm{R} \cdot \mathrm{T} 1$

dimana

$\mathrm{P} 1=\mathrm{P} 0=$ Tekanan ambaein.

$\mathrm{T} 1=\mathrm{T} 0=$ Temperatur ambaein

$\mathrm{m} 1=\mathrm{m} 0=$ nol (ideal nol, praktis mendekati nol)

Dalam proses ini, klep masuk membuka, sehingga sistem menyerap tenaga panas dari reservoir panas luar dengan suhu $25^{\circ} \mathrm{C}$, yakni karburator.

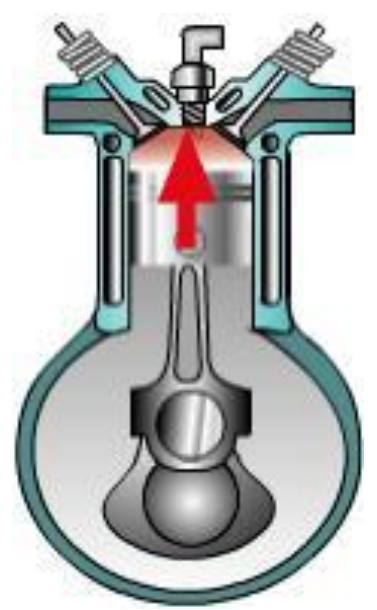

Gambar 3. Langkah Kompresi

Pada gambar 3 diatas terlihat langkah pemampatan gas campuran udara dan bahan bakar dalam silinder. Ketika pasangan klep dan piston naik 180 derajat sehingga ruang silinder mengecil. Dalam proses ini volume silinder dan volume gas (V) mengecil dari V1 ke V2, massa gas campuran bahan bakar dan udara tetap $\mathrm{m} 2$, tekanan gas $(\mathrm{P})$ meningkat naik dari P1 ke P2, dan suhu gas T meningkat naik dari T1 ke T2:

$(\mathrm{P} 2-\mathrm{P} 1) \cdot(\mathrm{V} 2-\mathrm{V} 1)=\mathrm{m} 2 \cdot \mathrm{R} \cdot(\mathrm{T} 2-\mathrm{T} 1)$ 
dimana gas dimampatkan, sehingga tekanan dan suhu gas meningkat sekitar 9,2 kali lipat. Perubahan volume berbanding terbalik dengan perubahan suhu, maka suhu meningkat.

$(\mathrm{V} 1 / \mathrm{V} 2)^{\wedge}(\mathrm{h}-1)=\mathrm{T} 1 / \mathrm{T} 2$

dimana

$\mathrm{h} \quad=$ panas jenis (spesific heat) gas campuran udara dan bahan bakar.

Untuk pendekatan ideal, $\mathrm{h}=2$, formula menjadi

$\mathrm{V} 1 / \mathrm{V} 2=\mathrm{T} 1 / \mathrm{T} 2$

$\mathrm{V} 1 . \mathrm{T} 2=\mathrm{V} 2 . \mathrm{T} 1$

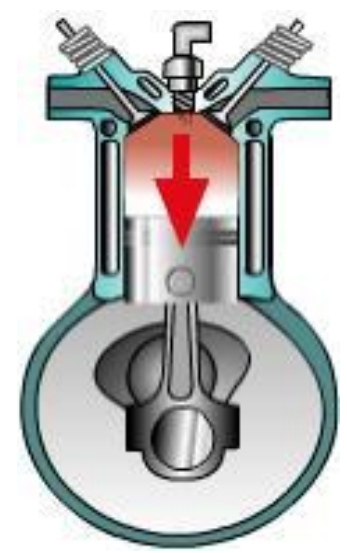

Gambar 4. Langkah Kerja

Pada gambar 4 diatas adalah proses penyalaan dan pembakaran gas campuran bahan bakar dan udara oleh percikan busi, ketika pasangan klep tertutup. Dalam proses ini, volume gas tetap pada V1, tapi karena pemanasan tekanan gas meningkat dari P2 ke P3, sehingga suhu gas meningkat naik dari T2 ke T3.

$(\mathrm{P} 3-\mathrm{P} 2) \cdot \mathrm{V} 1=\mathrm{m} 2 . \mathrm{R} \cdot(\mathrm{T} 3-\mathrm{T} 2)$

Gas dibakar, sehingga tekanan dan suhu gas meningkat sekitar 2,8 kali.

Pada proses ini pasangan klep tertutup, sehingga tak ada gas masuk ke dan keluar dari silinder, tapi silinder menerima panas dari ledakan gas campuran udara dan bahan bakar akibat percikan bunga api dari busi, sehingga T2 menjadi T3..

Kurva T3 - T4 adalah kurva fase proses adiabatik isentropik quasi-statik reversibel termodinamik, menggambarkan langkah pendayaan karena pembakaran gas campuran udara dan bahan bakar dalam silinder ketika pasangan klep tertutup sehingga piston turun 180 derajat dan ruang silinder membesar. Dalam proses adiabatik quasi-statik ini, volume silinder (V) membesar dari V1 ke V2, masa gas campuran tetap $\mathrm{m} 2$, tekanan gas $\mathrm{P}$ merosot turun dari $\mathrm{P} 3$ ke $\mathrm{P} 4$, dan suhu gas turun dari T3 ke T4

$(\mathrm{P} 3-\mathrm{P} 4)(\mathrm{V} 2-\mathrm{V} 1)=\mathrm{m} 2 . \mathrm{R} \cdot(\mathrm{T} 3-\mathrm{T} 4)$

Sehingga tekanan dan suhu gas merosot 1/9,2 kali lipat.

Perubahan volume berbanding terbalik dengan perubahan suhu, karenanya volume membesar dan suhu turun.

$(\mathrm{V} 1 / \mathrm{V} 2)^{\wedge}(\mathrm{h}-1)=\mathrm{T} 4 / \mathrm{T} 3$ 
dimana

$\mathrm{h} \quad=$ panas jenis (spesific heat) gas campuran udara dan bahanbakar.

Untuk pendekatan ideal, $\mathrm{h}=2$, formula menjadi

$\mathrm{V} 1 / \mathrm{V} 2=\mathrm{T} 4 / \mathrm{T} 3$ atau

$\mathrm{V} 1 . \mathrm{T} 3=\mathrm{V} 2 . \mathrm{T} 4$

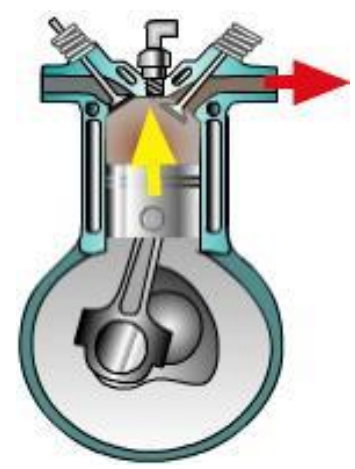

Gambar 5. Langkah Buang

Pada gambar 5 yaitu proses pendinginan dan pengeluaran atau pelepasan panas hasil pembakaran saat katup buang terbuka. Dalam proses ini volume gas V2, bobot gas campuran tetap m2, tekanan gas turun dari P4 ke P1, sehingga suhu gas turun dari $\mathrm{T} 4 \mathrm{ke} \mathrm{T} 1$.

$(\mathrm{P} 4-\mathrm{P} 1) . \mathrm{V} 2=\mathrm{m} 2 . \mathrm{R} .(\mathrm{T} 4-\mathrm{T} 1)$

Gas sisa pembakaran didinginkan sampai mencapai tekanan dan suhu udara luar, sehingga tekanan dan suhu turun 1/2,8 kali lipat.

Garis T1 - T0 pada gambar 1 adalah garis fase proses isobarik quasi-statik ireversibel termodimamik, menggambarkan langkah pembuangan sisa pembakaran, piston naik ruang silinder mengecil. Dalam proses isobarik quasistatik ini, dimana tekanan gas dan suhu gas tetap dan setara tekanan atmosfir karena klep buang terbuka. Volume silinder V mengecil dari V2 ke V1 sehingga bobot gas sisa pembakaran berkurang dari $\mathrm{m} 2 \mathrm{ke} \mathrm{m} 1$.

$\mathrm{P} 1$. $(\mathrm{V} 2-\mathrm{V} 1)=(\mathrm{m} 2-\mathrm{m} 1) \cdot \mathrm{R} \cdot \mathrm{T} 1$

Gas sisa pembakaran mencapai tekanan dan suhu udara luar dimana pada akhir proses volume dan molekul gas mendekati nol.

$\mathrm{P} 1 . \mathrm{V} 1=\mathrm{m} 1 . \mathrm{R}$. T1

Setelah 6 fase siklus Otto mesin 4-tak berakhir dan berulang kembali menjalani daur ulangnya. (http://www.mesinunila.org/images/favicon.ico )

\section{Specific fuel consumtion}

Data yang didapat dari percobaan akan diambil rata-ratanya dan dari hasil perhitungan daya motor akan digunakan sebagai pembagi dari bahan bakar yang dikonsumsi. Hasil ini dinamakan spesific fuel consumtion (SFC). Dengan sfc akan dianalisa pada angka yang terkecil, karena angka yang terkecil adalah konsumsi bahan bakar yang paling rendah.

$S F C=\frac{\text { fuel }}{\text { Torsi }}$ 
dimana :

Fuel : jumlah konsumsi bahan bakar per menit ( $\mathrm{ml} / \mathrm{menit})$

Torsi : daya puntir mesin (kg-m)

Untuk improvement dapat dihitung dengan persamaan berikut:

Improvement $=\frac{\Delta S F C}{\text { SFCnormal }} \times 100 \%$

dimana

$\triangle \mathrm{SFC} \quad=$ Selisih SFC terbaik dengan SFC normal

SFC normal $\quad=$ SFC pada keadaan standar

\section{Derajat Pengapian}

Timing pengapian sangat berpengaruh pada kualitas pembakaran. Sudut pengapian yang semakin awal akan menyebabkan laju kenaikan tekanan pembakaran semakin cepat, hal ini membuat semakin awal sudut penyemprotan semakin tinggi tekanan pembakaran dalam silinder. Jika timing pengapian terlambat, maka waktu yang dibutuhkan bahan bakar untuk terbakar menjadi sempit, bahan bakar dapat terbakar di knalpot atau saluran exhaust, hal ini yang sering menyebabkan pipa exhaust membara karena tinggi temperatur gas buang, sering sekali menjadi penyebab terjadinya derating pada prestasi motor bensin. (http://gudangilmu.org/wp-content/themes/silhouette/images/favicon.ico )

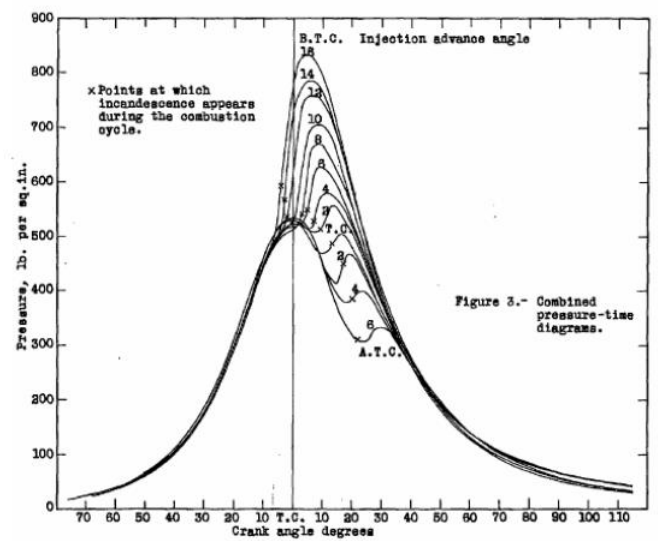

Gambar 6. Profil pembakaran dalam ruang bakar pada beberapa sudut

\section{Injeksi Air Pada Motor Bakar}

Panas adalah masalah utama pada mesin, dan dapat menyebabkan cepatnya kerusakan komponen mesin sehingga menurunkan performance mesin. Panas pada ruang bakar mesin bisa mencapai diatas $1100{ }^{\circ} \mathrm{C}$, apalagi jika mesin tersebut menggunakan Turbo atau Super Charger.

Water Injection adalah suatu teknik penyemprotan air kedalam ruang bakar sehingga jumlah bahan bakar yang dihisap oleh piston saat ekspansi bisa dikurangi dengan menggantikannya dengan injeksi air ke ruang bakar tersebut. Selain itu proses injeksi air ini dapat menurunkan suhu ruang bakar. Temperatur campuran minyak dan udara akibat bercampur dengan air diruang bakar akan menjadi lebih dingin. Penurunan temperatur ini akan menghasilkan energi yang lebih besar.

(http://en.wikipedia.org/favicon.ico) 
Beberapa keuntungan dari Water Injection yang bisa didapat :

a. Penyetelan campuran bensin seirit mungkin (LEAN).

b. Memungkinkan untuk menyetel Timing Pengapian lebih maju (Advance) untuk mendapatkan torsi yang lebih besar.

c. Menjaga ruang bakar tetap bersih, karena selalu terbilas oleh uap air tadi.

d. Mencegah atau mengurangi penumpukan Carbon di ruang bakar.

e. Menjaga stabilitas suhu mesin

f. Menghambat pembentukan NOx karena suhu ruang bakar yang tidak tinggi.

\section{METODOLOGI}

\section{Rancangan Percobaan}

Pengujian dilakukan beberapa kali dengan memvariasikan jenis air yang di injeksikan ke dalam ruang bakar. Selain itu perubahan derajat pengapian diberikan pada setiap penginjeksian. Dari proses pembakaran didapatkan daya yang berguna untuk memutar roda sepeda motor. Perputaran roda sepeda motor dimanfaatkan sebagai penggerak generator (tanpa beban). Daya listrik yang dibangkitkan generator akan diberi beban berupa lampu pijar.

Arus yang dihasilkan generator dikali dengan tegangan $(220 \mathrm{~V})$ dan $\cos \pi$ (asumsi= 1) kemudian dibagi 1000 akan menghasilkan daya generator dalam satuan kilo watt $(\mathrm{KW})$. Daya generator tersebut dikali dengan efisiensi total transmisi akan menghasilkan daya mesin sepeda motor.

Dengan mengalikan daya mesin dengan konstanta $9,47 \times 10^{5}$ dan membaginya dengan putaran mesin akan didapatkan torsi.

$$
\text { Torsi }=947000 \frac{N(K W)}{n(r p m)}(\mathrm{kg}-\mathrm{mm})
$$

dimana :

$\mathrm{N}$ = daya mesin motor

$\mathrm{n} \quad=$ putaran mesin motor

Kemudian dengan mengukur jumlah bahan bakar dan jumlah air yang masuk ke ruang bakar tiap menit pada setiap percobaan maka akan dapat diketahui setingan mesin yang paling efisien terhadap bahan bakar dengan tetap mempertahankan tenaga yang dibangkitkan mesin pada kondisi tanpa injeksi air.

\section{Prosedur Percobaan}

a. Sepeda motor diletakan diatas meja uji dan ban belakang sepeda motor berada diatas drum yang akan memutar generator

b. Injeksi air disambung ke intake manifold

c. Set derajat pengapian mesin sepeda motor.

d. Hidupkan mesin sepeda motor pada putaran generator (1500 rpm)

e. Generator diberi beban

f. Catat :

1) Jumlah bahan bakar yang dikonsumsi dalam satu menit

2) Jumlah air yang dikonsumsi dalam setiap menit

3) Arus listrik yang yang dihasilkan pada masing-masing beban sebanyak 3 kali

4) Rpm mesin sepeda motor

g. Ulangi penelitian pada beban $0,5 \mathrm{KW}, 1 \mathrm{KW}, 1,5 \mathrm{KW}$ dan $1,8 \mathrm{KW}$ 
h. Ulangi penelitian variasi injeksi yaitu air tanpa campur alkohol, air dengan campuran alkohol pada rasio 80:20 dan pada rasio 60:40

i. Ulangi penelitian pada derajat pengapian :

1) Mega Pro = Standar (17 derajat), maju 1 derajat dan maju 3 derajat

2) Supra Fit = Standar (15 derajat), maju 3 derajat dan maju 5 derajat

\section{PEMBAHASAN}

\section{Specific fuel Consumtion (SFC) Mega Pro Terhadap Torsi}

Pada gambar 7 diperlihatkan SFC pada beban 0,5 KW terhadap torsi. Pada gambar tersebut diperlihatkan bahwa pada beban 0,5 KW SFC terendah diberikan pada pengapian standar tanpa perlakuan injeksi air. Pada perlakuan tersebut dihasilkan SFC sebesar 21,71. Maka untuk menghasilkan $1 \mathrm{~kg}-\mathrm{m}$ torsi pada beban 0,5 KW dibutuhkan bahan bakar sebanyak $21,71 \mathrm{ml}$.

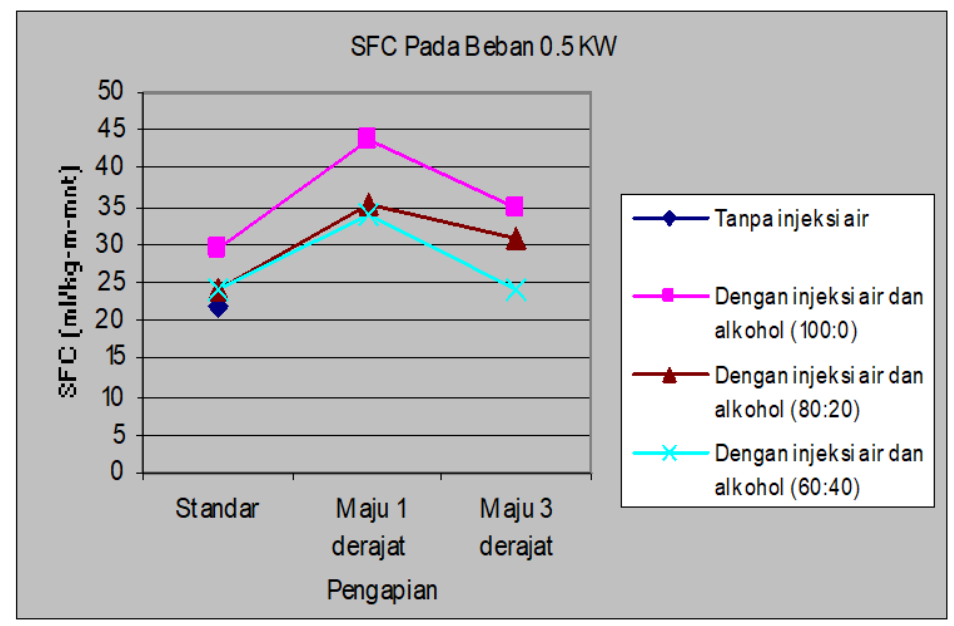

Gambar 7. Perbandingan SFC terhadap Torsi Pada Beban 0,5 KW

Pada gambar 8 dibawah ini diperlihatkan SFC pada beban $1 \mathrm{KW}$ terhadap torsi. Pada gambar teresebut diperlihatkan SFC terendah yang diberikan pada perlakuan injeksi air yang dicampur dengan alkohol pada rasio 60:40 dengan derajat pengapian yang dimajukan 3 derajat. Angka SFC terhadap torsi pada beban $1 \mathrm{KW}$ tersebut adalah 9,81. Sedangkan SFC tertinggi diberikan pada injeksi air dengan campuran alkohol pada rasio 80:20 dengan derajat pengapian yang dimajukan 3 derajat. 


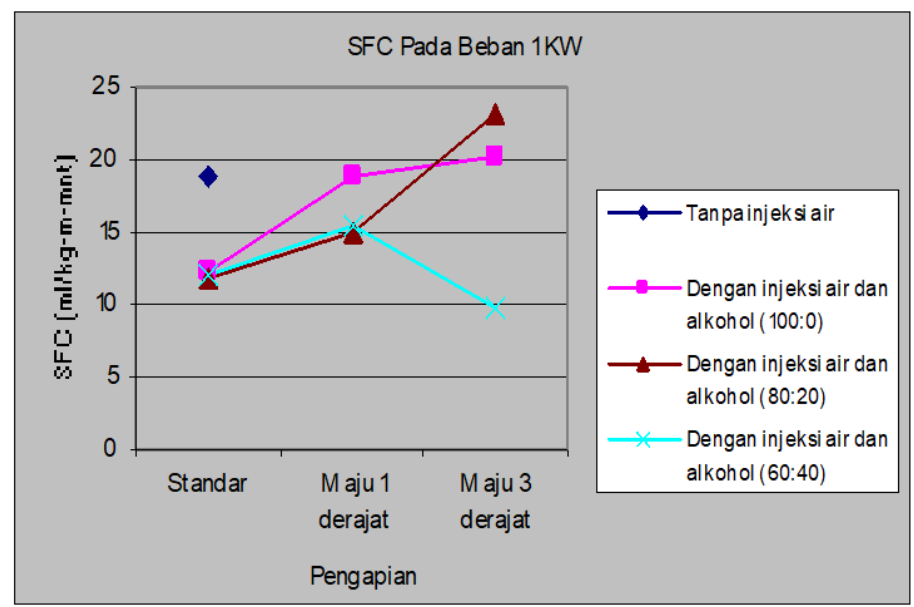

Gambar 8. Perbandingan SFC terhadap Torsi Mega Pro Pada Beban 1 KW

Pada gambar 9 diperlihatkan SFC pada Untuk beban 1,5 KW terhadap torsi. Pada gambar tersebut terlihat bahwa SFC pada perlakuan injeksi dengan campuran alkohol dengan rasio 60:40 pada derajat pengapian yang dimajukan 3 derajat menghasilkan SFC yang terendah.

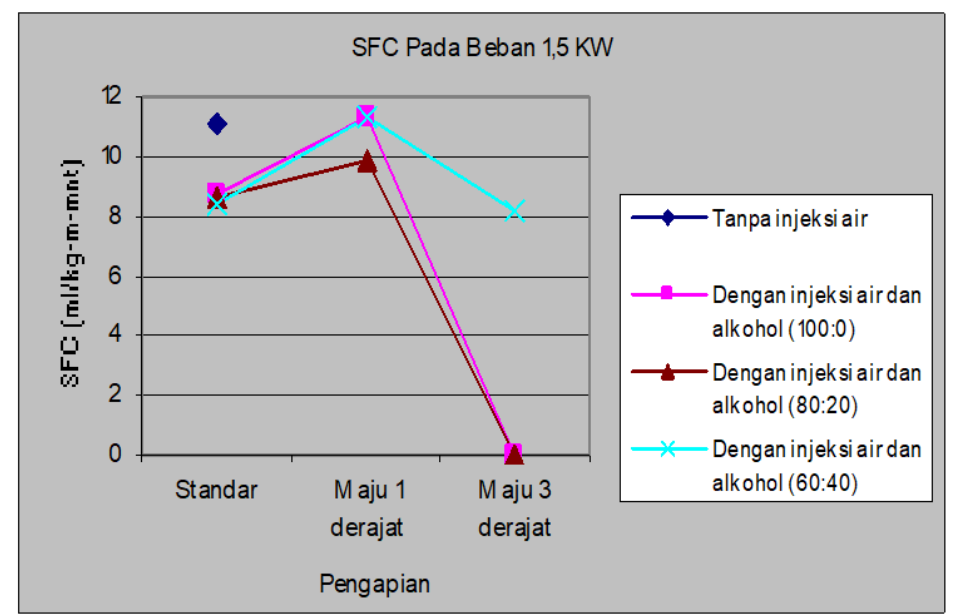

Gambar 9. Perbandingan SFC terhadap Torsi Mega Pro PadaBeban 1,5 KW

Pada gambar 10 diperlihatkan SFC pada beban 1,8 KW terhadap torsi. Pada Gambar dibawah ini diperlihatkan bahwa SFC terendah terjadi pada perlakuan injeksi air yang dicampur dengan alkohol pada rasio 60:40 dengan derajat pengapian yang dimajukan 3 derajat. Adapun angka SFC tersebut adalah 6,90. Dengan SFC tersebut maka perlakuan dan derajat pengapian inilah yang konsumsi bahan bakar terendah dalam menghasilkan $1 \mathrm{~kg}-\mathrm{m}$ torsi untuk pergerakan berputar pada sepeda motor. 


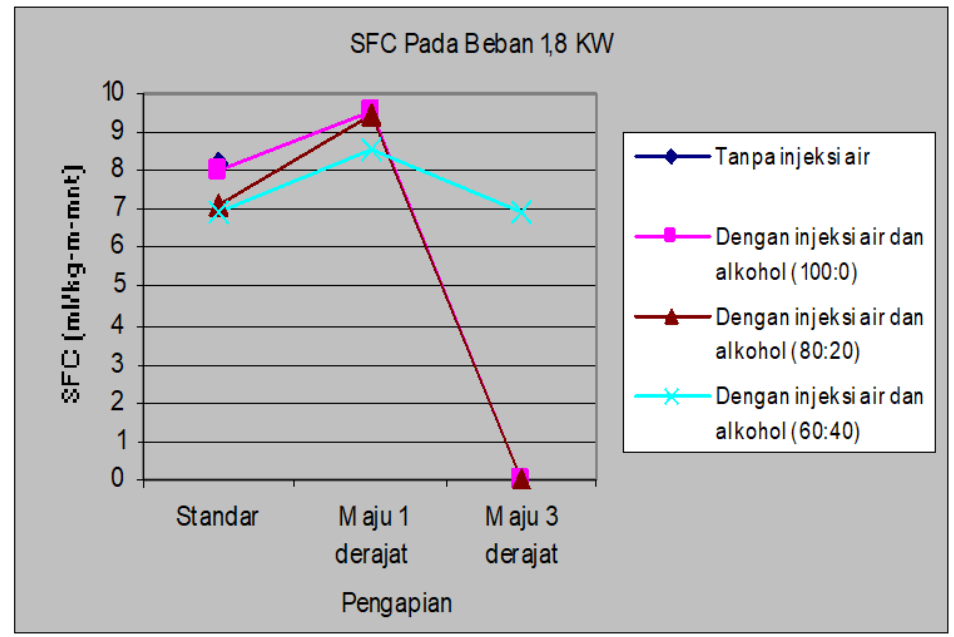

Gambar 10. Perbandingan SFC terhadap Torsi Mega Pro Pada Beban 1,8 KW

Dari hasil perhitungan SFC terhadap torsi diatas maka dikumpulkan angka-angka SFC terendah (bahan bakar yang diperlukan untuk menghasilkan torsi) dari setiap beban pada setiap perlakuan dan setiap derajat pengapian yang yang diberikan pada masing-masing beban. Selisih SFC standar dengan SFC terendah dibagi dengan SFC standar dihasilkan improve terhadap bahan bakar yang dikonsumsi dalam setiap torsi. Dari hasil perhitungan didapat bahwa untuk beban 0,5 KW mengalami pemborosan jika diberi injeksi, sedangkan untuk beban $1 \mathrm{KW}$ mengalami perbaikan sebesar 47,82\%. Pada beban 1,5 KW juga mengalami perbaikan konsumsi bahan bakar sebanyak 26,91\%. Untuk beban 1,8 KW terjadi perbaikan konsumsi bahan bakar sebanyak $15,75 \%$.

Dari pembahasan hasil SFC pada sepeda motor mega pro dapat dilihat secara keseluruhan seperti pada gambar 11 dibawah ini.

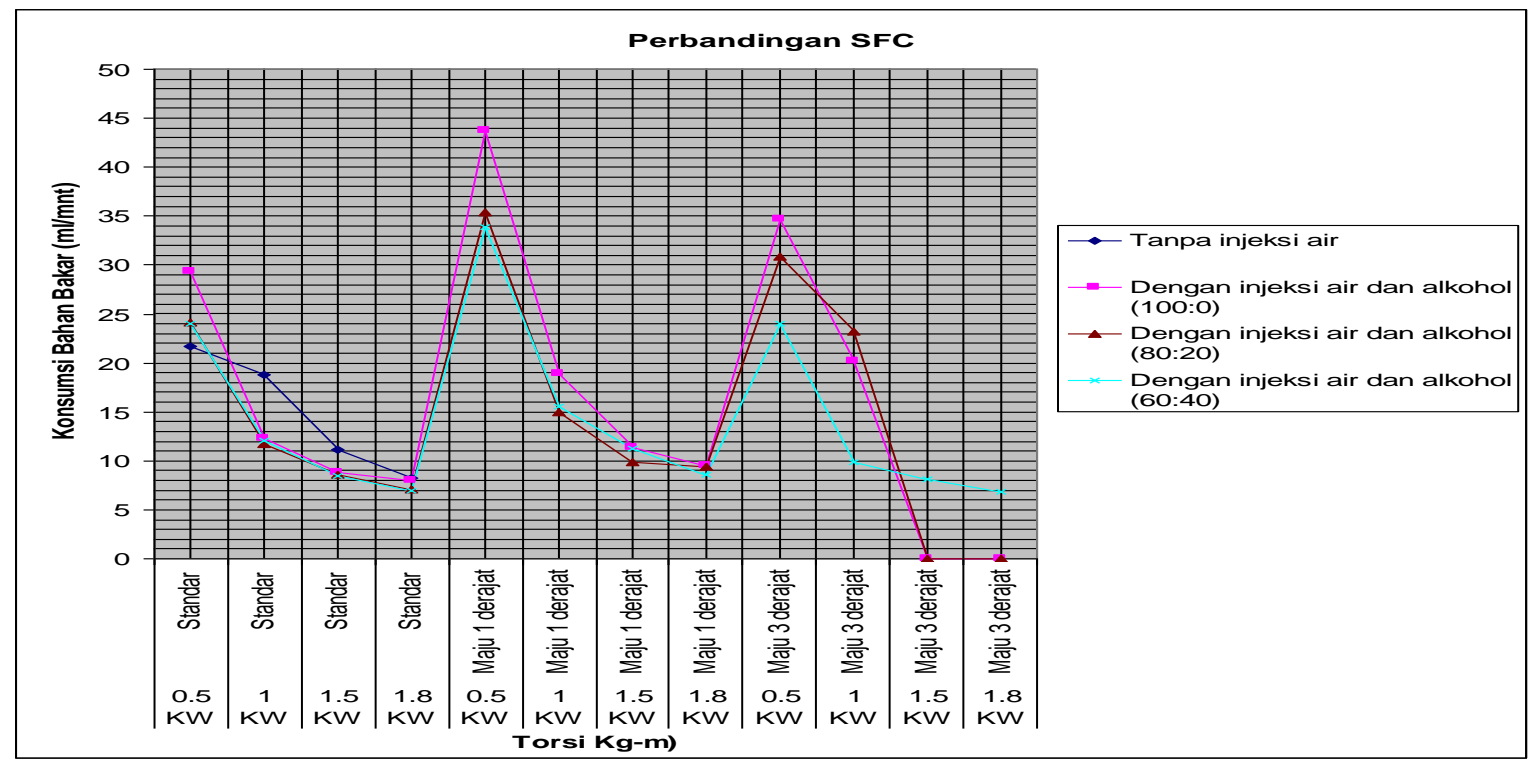

Gambar 11. Perbandingan SFC terhadap Torsi Mega pro 


\section{Specific fuel Consumtion (SFC) Supra Fit Terhadap Torsi}

Specific fuel consumtion (SFC) terhadap torsi adalah sejumlah bahan bakar yang dibutuhkan untuk menghasilkan torsi agar poros dapat berputar. Pada torsi ini putaran yang terjadi ikut menetukan besaran bahan bakar yang dibutuhkan. Pada gambar 12 dibawah ini diperlihatkan SFC pada beban $0,5 \mathrm{KW}$ terhadap torsi. Pada gambar tersebut diperlihatkan SFC terendah yang terjadi pada beban $0,5 \mathrm{KW}$. SFC terendah terjadi pada perlakuan injeksi air yang dicampur dengan alkohol pada rasio 80:20 dengan derajat pengapian maju 5 derajat. Angka SFC terendah pada beban $0,5 \mathrm{KW}$ tersebut adalah sebesar 30,88 .

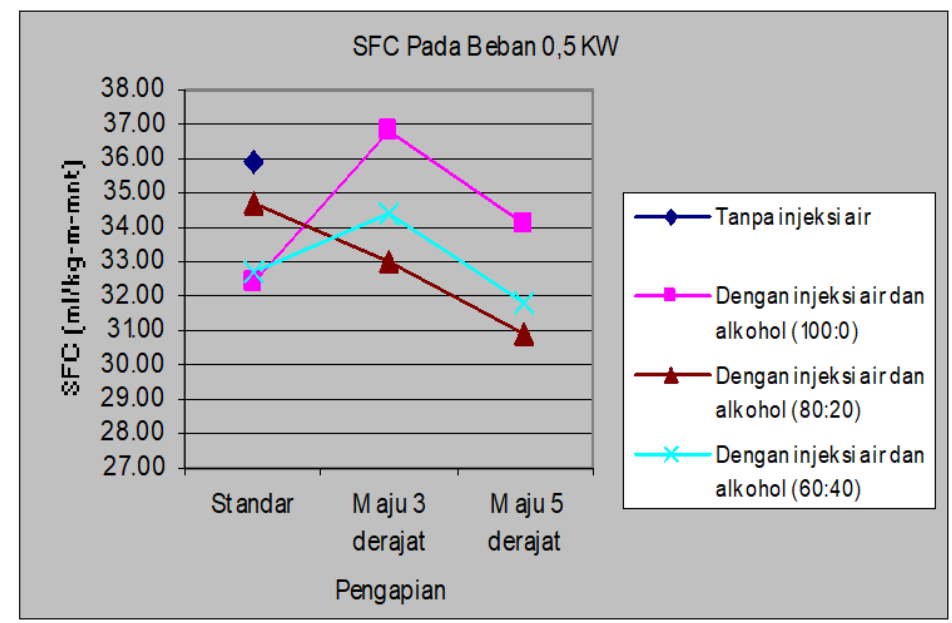

Gambar 12. Perbandingan SFC terhadap Torsi Supra Fit pada beban 0,5 KW

Pada gambar 13 dibawah ini ditampilkan SFC pada beban $1 \mathrm{KW}$ terhadap torsi. Pada gambar tersebut diperlihatkan bahwa perlakuan injeksi air dengan campuran alkohol pada rasio 80:20 menghasilkan SFC terendah pada derajat pengapian maju 5 derajat. Angka SFC yang terendah pada beban ini adalah sebesar 17,69 untuk setiap torsi yang dihasilkan.

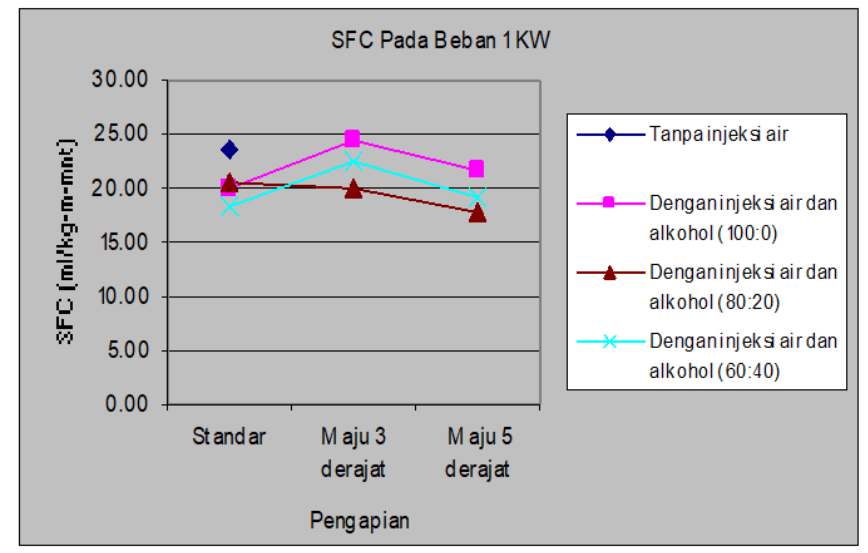

Gambar 13. Perbandingan SFC terhadap Torsi Supra Fit Pada Beban 1 KW 
Pada gambar 14 dibawah ini ditampilkan SFC pada beban 1,5 KW terhadap torsi. Pada gambar tersebut diperlihatkan bahwa perlakuan injeksi air yang dicampur alkohol pada rasio 60:40 untuk beban 1,5 KW dengan derajat pengapian standar menghasilkan SFC terendah yaitu sebesar 12,84.

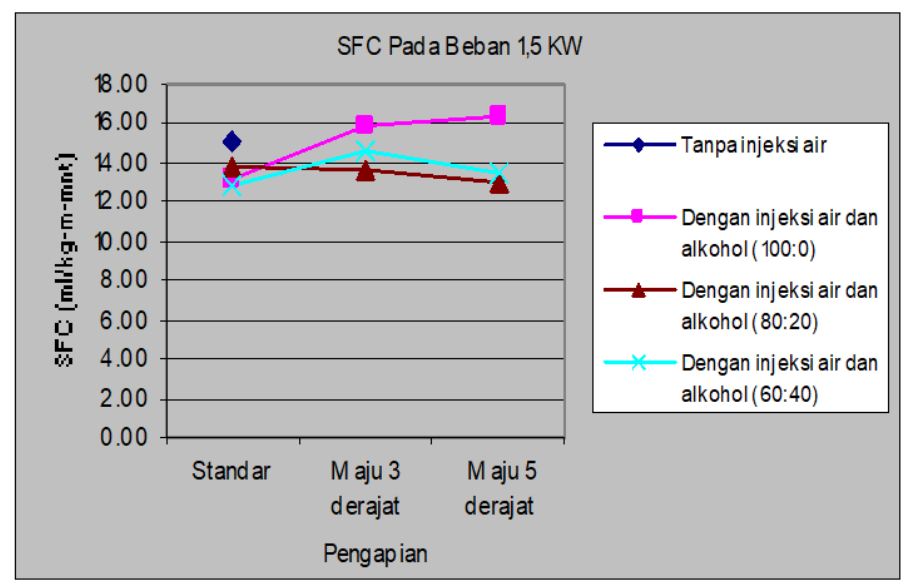

Gambar 14. Perbandingan SFC terhadap Torsi Supra Fit pada beban 1,5 KW

Pada gambar 15 dibawah ini diperlihatkan SFC pada beban 1,8 KW terhadap torsi. Pada gambar tersebut ditampilkan SFC terendah yang terjadi pada perlakuan injeksi air yang dicampur dengan alkohol pada pengapian maju 5 derajat. Pada perlakuan ini dihasilkan angka SFC terendah yaitu 9,65 untuk beban 1,8 KW.

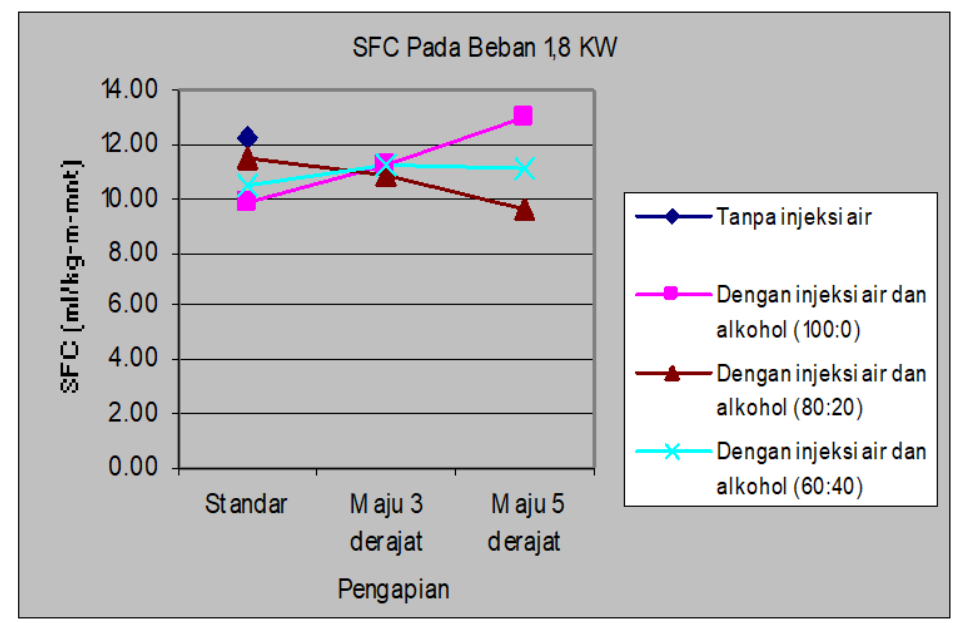

Gambar 15. Perbandingan SFC terhadap Torsi Supra Fit pada beban 1,8 KW

Dari hasil perhitungan SFC diatas maka dipilih SFC yang terendah yang terjadi pada setiap perlakuan dan setiap derajat pengapian pada setiap beban dan dikumpulkan Dari hasil perhitungan dapat ditampilkan seperti gambar 16 dibawah ini. Dari hasil pengumpulan tersebut terlihat bahwa pada beban 0,5 KW terjadi perbaikan konsumsi bahan bakar 13,96\%. Pada beban $1 \mathrm{KW}$ terjadi perbaikan konsumsi bahan bakar sebesar 25,14\%. Pada beban 1,5 KW terjadi perbaikan 
konsumsi sebesar $14,63 \%$ dan pada beban 1,8 KW terjadi perbaikan konsumsi bahan bakar sebesar $21,10 \%$.

Dari pembahasan hasil SFC pada sepeda motor supra fit dapat dilihat seperti pada gambar grafik dibawah ini.

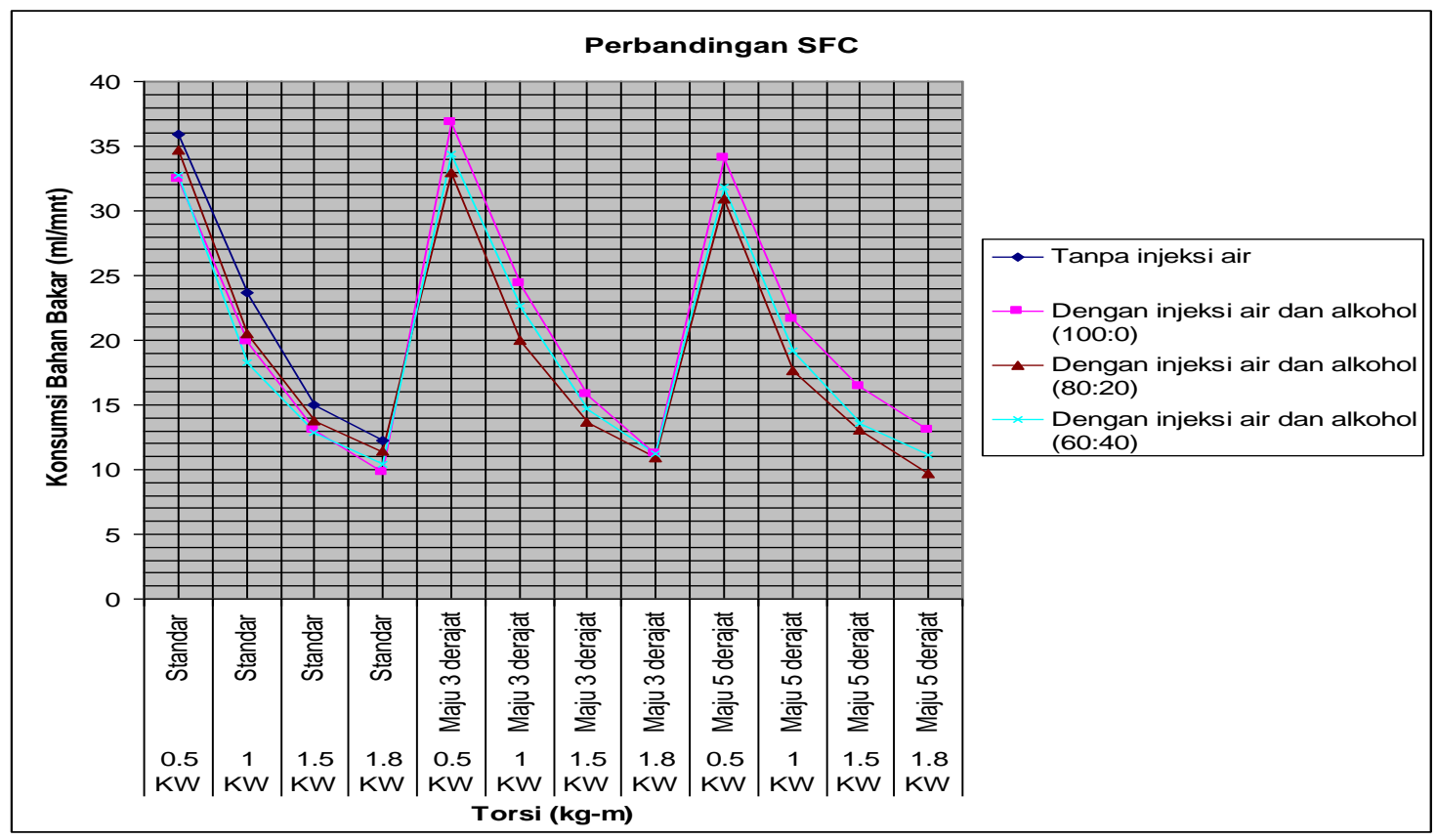

Gambar 16. Perbandingan SFC terhadap Torsi upra Fit

\section{SIMPULAN DAN SARAN \\ Simpulan}

Dari pembahasan yang dilakukan pada beberapa derajat pengapian dan beberapa perlakuan yang diberikan, baik pada mesin sepeda motor mega pro maupun mesin sepeda motor supra fit dapat disimpulkan sebagai berikut.

\section{Improvment Pada Honda Mega Pro}

Pada sepeda motor honda mega pro dengan memperhatikan SFC yang dibutuhkan untuk setiap Torsi yang dihasilkan maka dapat dipilih setingan yang terbaik yaitu injeksi air yang dicampur dengan alkohol pada rasio 60:40 dengan pengapian yang dimajukan 3 derajat. Penurunan konsumsi bahan bakar terjadi pada semua beban yang diberikan. Improve tertinggi terjadi pada beban $1 \mathrm{KW}$ yaitu 47,82\%. Improve terendah terjadi pada beban $0,5 \mathrm{KW}$ yaitu $-10,73 \%$.

\section{Improvement Pada Honda Supra Fit}

Pada sepeda motor honda supra fit dengan memperhatikan SFC yang dibutuhkan untuk setiap Torsi yang dihasilkan maka dapat dipilih setingan yang terbaik yaitu injeksi air yang dicampur dengan alkohol pada rasio 80:20 dengan pengapian yang dimajukan 5 derajat. Penurunan konsumsi bahan bakar terjadi pada semua beban yang diberikan. Improve tertinggi diberikan pada beban $1 \mathrm{KW}$ yaitu $25,14 \%$. Improve terendah diberikan pada beban $0,5 \mathrm{KW}$ yaitu $13,96 \%$.

\section{Saran}

Dari penelitian dan percobaan yang dilakukan terdapat beberapa kendala ketika melakukan pengambilan data. Disarankan untuk penelitian lebih lanjut. 
1. Gunakan peralatan alat ukur yang lebih akurat atau yang digital.

2. Generator yang digunakan sebagai pembangkit tenaga listrik diusahakan memiliki efisiensi yang jelas.

3. Sepeda motor yang digunakan untuk objek uji harus yang baru.

4. Objek uji diperbanyak pada kapasitas mesin yang berbeda.

\section{DAFTAR PUSTAKA}

"CRC Handbook of Chemistry and Physics",77th Edition, CRC Press, 1997, ISBN 08493-0477-6.

Better-mileage.com,'Improve energy efficiency in vehicles", CRC Press 1997

Eric Fahlgren,"Water Injection Thermodynamics", Mcgraw-Hill new york 19/9/2003

www.Karlsnet.com ,"Water Injection Project", 5/2/2002

David Lewis,"Water Injection For Your Turbo", Delmar Purlishers Inc, 1998

Dawes,"Do-It-Yourself Water/Alcohol Injection System and Intercooler Sprayer", 21/3/2000

Robert Mann,'Water Injection", 27/9/2001, Revised 07/7/2003

Ron Novak,"Do-It-Yourself Water Injection System", 1980

Heinicke, Orville,"Nasa Water-Alcohol Injection Reports", NACA WR-E-264 NACA-MR-E5H12, August 1945 20/5/2007

Maleev, M.L. Internal Combustion Engine, 2nd ed. Singapore : McGraw - Hill Book Co,Inc, 1973.

M.M. El-Wakil, "Powerplant Technology”, McGraw-Hill Book Company, 1984

Sularso, Kiyokatsu Suga,"Dasar Perencanaan dan Pemilihan Elemen Mesin”, Pradnya Paramita, Jakarta 1985

www.energyefficiencyasia.org CUNEP, "Pedoman Efisiensi Energi untuk Industri di Asia" 25/12/2007

Notodisuryo, Endro Utomo,"Kebijakan Konservasi energi nasional (Makalah Seminar Energi", Jakarta; Direktorat Pengembangan Energi Baru Departemen Pertambangan dan Energi Indonesia, 3/9/1991

Adrian Bejan, "Advanced Engineering Thermodynamic", Jhon Wiley\&son. Inc 1988

Roger Kinsky M.Eng,Sc.,B.E.,B.Sc, "Applied Heat”, ,An Introduction to thermodynamics, Mcgraw-Hill new york Second edition, 1985

Arismunandar, Wiranto,'Penggerak Mula: Motor Bakar Torak", Penerbit ITB, Edisi kelima cetakan kesatu, Bandung, 2000.

Arends, BPM., dan Barendschot, H., "Motor Bensin", Penerbit Erlangga Jakarta, 2000

Cengel, Yunus A., dan Boles, Michael A., "Thermodynamic: An Engineering Approach", Mc. Graw-Hill Inc., United State of America, 1994

Anonim, "Petunjuk Praktikum Motor Bakar", Laboratorium Konversi Energi , Jurusan Teknik Mesin, Fakultas Teknik UGM, 2000

Indartono, Yuli, "Bio-ethanol Alternatif Energi Terbarukan: Kajian Prestasi Mesin dan Implementasi di Lapangan",

http://www.energi.lipi.go.id , 2000.

http://mekanisasi.litbang.deptan.go.id/index2.php?option=com_content\&do_pdf=1\&i $\mathrm{d}=246 / 19 / 5 / 2008$

http://www.afdc.doe.gov. 12/12/2007

http://www.energi.lipi.go.id 12/12/ 2007 
http://www.ethanol.org 25/122007

http://journeytoforever.org/biofuel_library/ethanol_motherearth 5/1/2008

Course, William.H, “Automotive Elecrical Equipmen”t, 4th ed. New York : McGraw HillBook Co, Inc, 1959.

Heywood, Jhon.B, “Internal Combustion Engine Fundamentals”, Mcgraw Hill Book Co, Inc, Singapore 1989.

Kristanto, Pihlip, "Buku Pedoman Praktikum Motor Bakar", Surabaya : U.K. PETRA, 1998

Santini, Al, "Automotive Electrical and Electronics", New York : Delmar Purlishers Inc, 1998.

Tirtoatmodjo, Rahardjo, "Penggerak Mula", ed 1. Surabaya : CV. Citra Media, 2000.

Wijaya, Barata, "Perencanaan Pegas Centrifugal Advance Dari Daiharsu CB-23 Jika Menggunakan Bahan Bakar Gas. Surabaya”, Universitas Kristen Petra, 1996.

http://www.tempointeraktif.com 4/9/2006

http://www.digilib.petra.ac.id/dual_fuel-resource1.pdf 12/10/2007

http://www.udarakota.bappenas.go.id/images/kupukupu.gif /4/5/2005

http://www.pikiran-rakyat.com/karakteristiceuro2/23/8/2006

http://www.mesinunila.org/images/favicon.ico 5/8/2007 